\title{
Risk Factors and the Usual Source of Care on Non-Adherence to Antihypertensive Drugs in Immigrants with Hypertension
}

This article was published in the following Dove Press journal: Patient Preference and Adherence

\author{
Hyemin Cho $\mathbb{D}^{1, *}$ \\ Sohyun Jeong ${ }^{2,3, *}$ \\ Cinoo Kang $\mathbb{I D}^{4}$ \\ Hee-Jin Kang' \\ Suhyun Jang' \\ Sunmee Jang' \\ 'College of Pharmacy and Gachon \\ Institute of Pharmaceutical Sciences, \\ Gachon University, Incheon, Republic of \\ Korea; ${ }^{2}$ Marcus Institute for Aging \\ Research, Hebrew SeniorLife, Boston, \\ MA, USA; ${ }^{3}$ Department of Medicine, \\ Beth Israel Deaconess Medical Center \\ and Harvard Medical School, Boston, MA, \\ USA; ${ }^{4}$ Department of Biostatics and \\ Epidemiology, Graduate School of Public \\ Health, Seoul National University, Seoul, \\ Republic of Korea
}

*These authors contributed equally to this work
Correspondence: Sunmee Jang College of Pharmacy and Gachon Institute of Pharmaceutical Sciences, Gachon University, I9I Hambakmoero, Yeonsu$\mathrm{Gu}$, Incheon 21936, South Korea

Tel +82-32-820-494I

Fax +82-32-820-4829

Email smjang@gachon.ac.kr
Background: Immigrants are vulnerable to suboptimal health care utilization including nonadherence of medication use. Thus, we aimed to identify the potential risk factors of nonadherence and evaluate whether utilizing a usual source of care was associated with medication adherence in immigrants.

Methods: We utilized the Korea National Health Insurance Claims Database between 2012 and 2015. Cases were immigrants who had antihypertensive prescriptions at the time of hypertension diagnosis in 2012. Controls were native-born Koreans with hypertension who were 1:1 matched to immigrants by age, sex, and Charlson comorbidity index. We used the medication possession ratio for three years to assess the adherence to antihypertensive drugs. The likelihood of non-adherence was evaluated between cases and controls by multivariate linear regression models stratified by age, sex, and number of clinic visits. We assessed the potential risk factors of non-adherence in immigrants by multivariate linear regression and logistic regression models, respectively.

Results: In total, 4114 immigrants and 4114 matched native-born Koreans with hypertension were included. The mean MPR was significantly lower in immigrants $(56 \%$ vs $70 \%$, $p<0.0001)$. Immigrants showed almost two times the level of non-adherence as native-born Koreans (odds ratio [OR], 2.01; 95\% confidence interval [CI], 1.83-2.21). Stratified analyses on non-adherence presented the highest non-adherence (2.28 times) in immigrants in the younger group (30-49 years old) and the lowest non-adherence in immigrants in 65 and old group where the risk was 1.69 times higher than native Korean with the same age. The absence of a usual source of care significantly increased medication non-adherence by 1.31 to 1.58 times among immigrants.

Conclusion: When the number of visited clinics increased, the degree of non-adherence increased consistently. Therefore, the systematization of registering with primary care (a usual source of care) might be a modifiable health care strategy to improve health care outcomes in immigrants.

Keywords: usual source of care, hypertension, immigrants, health care strategy

\section{Introduction}

Immigrants are a minority group that experiences inequities in health outcomes. Extensive migration during the past 100 years has changed many regions of the world and posed new challenges, including challenges on health care services and policies to facilitate the smooth acculturation of immigrants. ${ }^{1,2}$ Risk factors for suboptimal health care outcomes in immigrants include low socioeconomic status, passive health care-seeking behaviors, low access to care due to language and 
knowledge barriers, and other unrecognized factors derived from the health system or health care workers. ${ }^{3}$ As immigrants usually move from under-developed settings to industrial and urbanized societies, ${ }^{1}$ the resultant environmental shift might cause an increased risk of cardiovascular disease (CVD) in immigrants comparable to the level presented in developed countries.

CVD has been the global leading cause of death for the last 15 years. ${ }^{4}$ As the treatment of hypertension is associated with a $20 \%$ to $25 \%$ reduction in $\mathrm{CVD},{ }^{5}$ hypertension management is an essential aspect of reducing the high burden of CVD-associated mortality. Although significant improvements in the screening and treatment of hypertension have been achieved in recent years, health care disparities persist among different social, economic, and ethnic groups. ${ }^{6}$ In the USA, among treated patients, a smaller proportion (49.7\%) of black men achieved hypertension control than white men $(65.0 \%)$ in $2018 .^{6}$ Immigrants from China showed a lower rate of hypertension treatment than native Italians, despite a similar rate of awareness of the disease. ${ }^{7}$

Korea is no longer a racially and ethnically homogeneous country and not an exception from other advanced countries that have confronted health care disparity problems that emerged by certain racial and immigrant groups. The number of immigrants in Korea has increased rapidly, reaching 2.3 million in 2018 (4.6\% of the population). ${ }^{8}$ The health care problems of immigrants may pose increasing economic and societal burdens on the future health care system. Adequate health insurance and policies facilitate the utilization of preventive services and improve general health, physical functioning, and health outcomes in individuals with acute and chronic diseases. ${ }^{9}$ Well adopted health care policies have been associated with a $40 \%$ decreased risk of premature death $^{10}$ in the USA. Thus establishing a robust and promising health care plan in advance for immigrants should be an important strategy of future-oriented policy-making as well.

Medication non-adherence is a leading cause of inadequate hypertension management, which results in CVD, stroke, and chronic kidney disease. ${ }^{11}$ About $50 \%$ of patients with CVD have suboptimal adherence to their prescribed medications, with unfavorable effects on morbidity, mortality, and healthcare expenditures. ${ }^{12,13}$ Approximately 25-30\% of Korean adults have hypertension ${ }^{14}$ and the rate of antihypertensive adherence is approximately $47.7 \%$ to $57.4 \%{ }^{15,16}$ However, no research has yet investigated the epidemiological characteristics of hypertension among immigrants in Korea and their adherence to hypertension treatment. Culture and psychosocial factors play a role in adherence behavior, ${ }^{17}$ although the competency and infrastructure of the host country's health care system matter as well.

In particular, having a usual source of care, such as a family physician, is closely associated with high medication adherence in the USA, ${ }^{18,19} \mathrm{Canada}^{20}{ }^{20} \mathrm{Kuwait}^{21}$ and Bosnia. $^{22}$ Therefore, we hypothesized that medication adherence would be relatively low in immigrants due to the barriers they face in terms of utilizing stable medical services, which are caused by both the unmet needs of the overall medical system of Korea (as having a usual source of health care is not systematized) and the health care access barriers that immigrants encounter in general. ${ }^{3}$ Therefore, we aimed to compare differences in medication adherence for hypertension management between immigrants and native-born Koreans and to assess potential risk factors by a population-based retrospective cohort study.

\section{Methods}

\section{Data Source}

Health care data for immigrants and native-born Koreans were retrieved from the Korean National Health Insurance Claims Database (KNHICD) between 2012 and 2015. The KNHICD covers approximately $97 \%$ of the whole Korean population and includes eligible immigrants through the mandatory health care insurance subscription system. The remaining $3 \%$ of the population is covered by Medical Aid, a governmental health care assistance program for the economically unprivileged. The KNHICD offers information on the International Classification of Diseases, 10th revision (ICD-10) diagnosis codes, medication profile, hospital information, inpatient and outpatient visits, and surgical and operational codes.

This study was approved by the Gachon University Institutional Review Board (IRB No. 1044396-201710HR-169-10). The study has been conducted following legal and regulatory requirements described in "Guidelines for Good Database Selection and Use in Pharmacoepidemiology Research" 23 on patient personal data and did not include any individual patient information. KNHICD protects personal information and privacy by encrypting claims data and only provides anonymized individual data to the requested entity under stringent regulation and procedure. 


\section{Subject (Inclusion and Exclusion Criteria)}

We selected immigrants and native-born Koreans who had antihypertensive prescriptions at the time of hypertension diagnosis (ICD-10: I10, I11, I12, I13, I15) in 2012. The inclusion criterion for immigrants was eligibility to receive ongoing Korean National Health Insurance benefits, so only immigrants with stable resident status (permanent residents, naturalized residents, and marriage immigrants) were included. Patients who had diagnosed with hypertension in the previous 1-year period were excluded to include cases of new-user with antihypertensive drugs. Additionally, patients who were younger than 30 years old, had fewer than 2 clinic visits, or died during the 3-year follow-up period were excluded. Among the selected patients, immigrants and native-born Koreans were 1:1-matched by a propensity score based on age, sex, and the Charlson comorbidity index (CCI) score. The index date for both groups was defined as the date when the first hypertension diagnosis code was captured. Both groups were followed for 3 years.

\section{Definition of Variables Medication Adherence}

Medication adherence was measured by the medication possession ratio (MPR), which is the most widely established tool for measuring medication adherence. ${ }^{24}$ In this study, we calculated MPR based on prescription data (prescription days of antihypertensive medications) available from KNHICD. Since a previous Korean study suggested that an MPR of less than $80 \%$ for antihypertensives was associated with a 1.93 times higher incidence of cerebrocardiovascular disease,${ }^{15,25}$ adherence was defined as an MPR $\geq 80 \%$ and non-adherence was defined as an MPR $<80 \%$. The MPR was observed for 3 years from the index date (the first prescription date of antihypertensive medication) every 6 months. The MPR was calculated as MPR $(\%)=$ total sum of prescription days/follow-up days $\times 100$.

\section{Usual Source of Care}

Having a usual source of care was evaluated as a proxy of stable health care utilization during the follow-up period. The number of visited clinics was used as the index of having a usual source of care. For example, if a patient visited clinic A 3 times, and clinic B 2 times during the follow-up period, the number of care sources would be 2 .

\section{Confounding Variables}

We selected potential confounding variables, including sex, age, immigration status (permanent resident, naturalized resident, or marriage immigrant), type of health insurance (Medical Aid or National Health Insurance; Medical Aid: full coverage by the National Health Insurance System; NHI: approximately $70 \%$ coverage for all medical expenditures, with patients paying for $30 \%$ of costs out of pocket), residential area, living alone, comorbidities, the number of antihypertensive medications (an indicator of the disease severity of hypertension). The level of insurance contribution represented financial status because the insurance contribution for NHI is calculated based on income using a predefined method (a fixed percentage of salary for employees and a score calculated based on assets for the self-employed). The NHI divides insurance contributions into 20 quantiles where high quantiles correspond to high payments (and high income). Medical Aid is defined as the 0 th quantile. We categorized insurance contributions into three groups: low (0-6), middle (7-15), and high (16-20).

Comorbidity was defined as having a principal diagnosis (ICD-10 code) accompanied by 2 and more outpatient visits or 1 and more inpatient or undergoing surgical treatment within 1 year of the index date. The ICD-10 codes of the included comorbidities related to hypertension were as follows: nephropathy (N18, N19, N25, N28.9, Z49，Z99.2，Z94.0，V005; operational code: R3280), cerebrovascular disease (G45, I63, I65, I66), cardiovascular disease (I20, I21, I22 I23, I24, I25, I50, I70, I71; operational codes: M6551, M6552, M6561, M6562, M6563, M6564, M6567, O1641, O1642, O1647, OA641, and OS647), and peripheral vascular disease (I73.8, I73.9, I77.1, I79.2, I798, K55.1, K55.8, K55.9, Z95.8, Z95.9). Of particular note, we also considered subjects who were diagnosed with diabetes (E11, E12, E13, E14) within the year before the index date. Diabetes requires daily use of medicine, like hypertension, so we included diabetes as a confounder because it could affect adherence to antihypertensive drugs.

\section{Statistical Analyses}

The baseline characteristics of the included subjects are presented as counts with percentages for categorical data and as means with standard deviations for continuous data. Categorical data were evaluated by the chi-square test and continuous variables were assessed by the $t$-test. Medication adherence as a whole was compared between immigrants and native-born Koreans with multivariate linear regression analysis. Additionally, we stratified the cases and controls into age, sex, and number of clinic visits and evaluated the risk of non-adherence with multivariate linear regression models on 
each subgroup, which identified contributing factors to the difference in medication adherence. To explore potential risk factors for non-adherence in antihypertensives among immigrants, logistic regression analysis was conducted. Odds ratios (ORs) and the corresponding 95\% confidence intervals (CIs) were estimated, adjusting for possible confounders (covariates that were statistically significantly different at baseline). All statistical analyses were performed using SAS 9.3 (SAS Institute Inc., Cary, NC, USA) and a 2-tailed level of statistical significance was defined as a $p$-value $<0.05$.

\section{Results}

A total of 4114 immigrants with hypertension and 1:1 age, sex, and CCI score-matched native-born Koreans $(n=4114)$ with hypertension were included in the study (Figure 1). The demographic profile of the immigrants showed that being female (56.8\%), being 50-64 years old (40.3\%), having naturalized status (58.4\%), and residing in an urban area (95.6\%) were prevalent characteristics (Table 1). A higher proportion of immigrants $(95.6 \%)$ resided in urban areas than their native-born Korean counterparts (89.2\%). Immigrants were more likely to have Medical Aid status (6.8\%) than native-born Koreans (3.2\%). Many more immigrants were in the lowest level of insurance contributions $(47.5 \%$ vs. $28.1 \%$ ), and correspondingly, many fewer immigrants were in the highest level of insurance contributions ( $9 \%$ vs. 33\%). The type of insurance and level of insurance contribution coherently indicated that the immigrants had lower financial status than their native-born Korean counterparts. More immigrants lived in urban areas by themselves. Comorbidities were more prevalent in native-born Koreans $(3.8 \%$ vs. $7.9 \%)$ and the prevalence of diabetes was also higher in native-born Koreans (3.4\% vs. 5.6\%). Immigrant visited more clinics for hypertension treatment than nativeborn Korean patients, as $15.7 \%$ of immigrants visited $\geq 6$ clinics, whereas this was only the case for $9.2 \%$ of nativeborn Koreans. Visiting 1 or 2 clinics was defined as having a stable usual source of care, and it was more prevalent in native-born Koreans (36.2\% for immigrants vs. $47.6 \%$ for native-born Koreans).

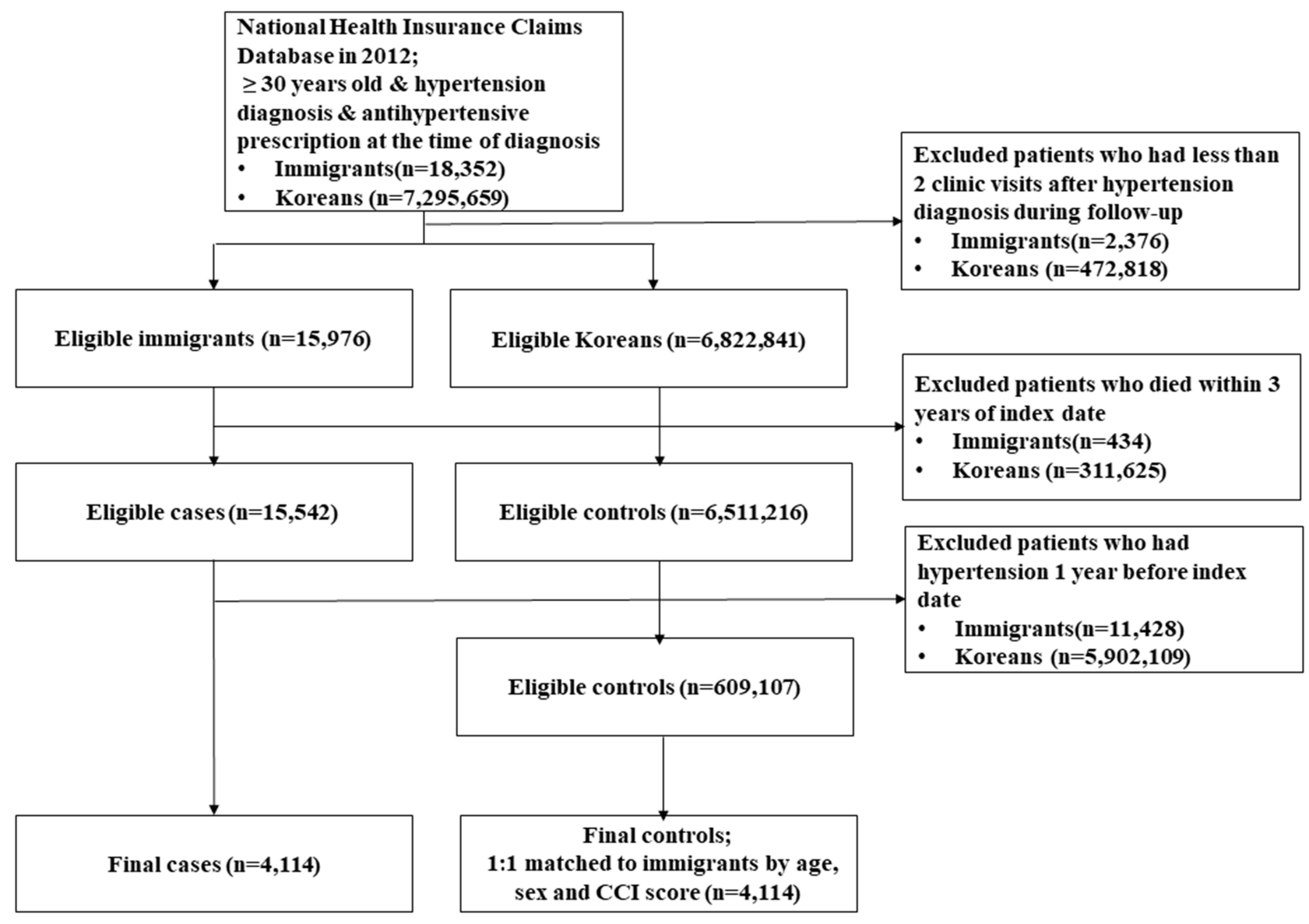

Figure I Flow diagram of the selection process of study subjects. 
Table I Baseline Characteristics of Immigrants and Native-Born Koreans with Hypertension Included in the Study

\begin{tabular}{|c|c|c|c|c|c|c|c|c|}
\hline \multirow{2}{*}{\multicolumn{2}{|c|}{ Variables }} & \multicolumn{2}{|c|}{$\begin{array}{l}\text { Total } \\
(n=8228)\end{array}$} & \multicolumn{2}{|c|}{$\begin{array}{l}\text { Immigrants } \\
(n=4|| 4)\end{array}$} & \multicolumn{2}{|c|}{$\begin{array}{l}\text { Native-Born } \\
\text { Koreans }(n=4|| 4)\end{array}$} & \multirow{3}{*}{$\begin{array}{l}\text { P-value } \\
0.9114\end{array}$} \\
\hline & & \multirow{2}{*}{$\begin{array}{l}\mathbf{N} \\
3559 \\
4669\end{array}$} & \multirow{2}{*}{$\begin{array}{l}\% \\
43.25 \\
56.75\end{array}$} & \multirow{2}{*}{$\begin{array}{l}\mathbf{N} \\
1777 \\
2337\end{array}$} & \multirow{2}{*}{$\begin{array}{l}\% \\
43.19 \\
56.81\end{array}$} & \multirow{2}{*}{$\begin{array}{l}\mathbf{N} \\
1782 \\
2332\end{array}$} & \multirow{2}{*}{$\begin{array}{l}\% \\
43.32 \\
56.68\end{array}$} & \\
\hline Sex & $\begin{array}{l}\text { Male } \\
\text { Female }\end{array}$ & & & & & & & \\
\hline Age & $\begin{array}{l}30-49 \text { years } \\
50 \sim 64 \text { years } \\
65-74 \text { years } \\
\geq 75 \text { years }\end{array}$ & $\begin{array}{l}2859 \\
3376 \\
1417 \\
702\end{array}$ & $\begin{array}{l}34.75 \\
41.03 \\
17.22 \\
8.53\end{array}$ & $\begin{array}{l}1425 \\
1683 \\
715 \\
354\end{array}$ & $\begin{array}{l}34.64 \\
40.91 \\
17.38 \\
8.60\end{array}$ & $\begin{array}{l}1434 \\
1693 \\
702 \\
348\end{array}$ & $\begin{array}{l}34.86 \\
41.15 \\
17.06 \\
8.46\end{array}$ & 0.9729 \\
\hline Residential area & $\begin{array}{l}\text { City } \\
\text { Rural area }\end{array}$ & $\begin{array}{l}7602 \\
626\end{array}$ & $\begin{array}{l}92.39 \\
7.61\end{array}$ & $\begin{array}{l}3933 \\
181\end{array}$ & $\begin{array}{l}95.60 \\
4.40\end{array}$ & $\begin{array}{l}3669 \\
445\end{array}$ & $\begin{array}{l}89.18 \\
10.82\end{array}$ & $<0.0001$ \\
\hline Type of insurance & $\begin{array}{l}\text { National Health Insurance } \\
\text { Medical Aid }\end{array}$ & $\begin{array}{l}7814 \\
414\end{array}$ & $\begin{array}{l}94.97 \\
5.03\end{array}$ & $\begin{array}{l}3833 \\
281\end{array}$ & $\begin{array}{l}93.17 \\
6.83\end{array}$ & $\begin{array}{l}3981 \\
133\end{array}$ & $\begin{array}{l}96.77 \\
3.23\end{array}$ & $<0.0001$ \\
\hline Level of insurance contribution & $\begin{array}{l}\text { Low } \\
\text { Middle } \\
\text { High }\end{array}$ & $\begin{array}{l}3108 \\
3392 \\
1728\end{array}$ & $\begin{array}{l}37.77 \\
41.23 \\
21.00\end{array}$ & $\begin{array}{l}1954 \\
1791 \\
369\end{array}$ & $\begin{array}{l}47.50 \\
43.53 \\
8.97\end{array}$ & $\begin{array}{l}1154 \\
1601 \\
1359\end{array}$ & $\begin{array}{l}28.05 \\
38.92 \\
33.03\end{array}$ & $<0.0001$ \\
\hline Number of household members & $\begin{array}{l}I \text { (self) } \\
\geq 2\end{array}$ & $\begin{array}{l}2400 \\
5828\end{array}$ & $\begin{array}{l}29.17 \\
70.83\end{array}$ & $\begin{array}{l}1515 \\
2599\end{array}$ & $\begin{array}{l}36.83 \\
63.17\end{array}$ & $\begin{array}{l}885 \\
3229\end{array}$ & $\begin{array}{l}21.51 \\
78.49\end{array}$ & $<0.000$ I \\
\hline $\mathrm{CCl}$ & $\begin{array}{l}0 \\
\geq 1\end{array}$ & $\begin{array}{l}5794 \\
2434\end{array}$ & $\begin{array}{l}70.42 \\
29.58\end{array}$ & $\begin{array}{l}2916 \\
1198\end{array}$ & $\begin{array}{l}70.88 \\
29.12\end{array}$ & $\begin{array}{l}2878 \\
1236\end{array}$ & $\begin{array}{l}69.96 \\
30.04\end{array}$ & 0.3066 \\
\hline Comorbidities & $\begin{array}{l}\text { No } \\
\text { Yes }\end{array}$ & $\begin{array}{l}7745 \\
483\end{array}$ & $\begin{array}{l}94.13 \\
5.87\end{array}$ & $\begin{array}{l}3958 \\
156\end{array}$ & $\begin{array}{l}96.21 \\
3.79\end{array}$ & $\begin{array}{l}3787 \\
327\end{array}$ & $\begin{array}{l}92.05 \\
7.95\end{array}$ & $<0.0001$ \\
\hline Diabetes & $\begin{array}{l}\text { No } \\
\text { Yes }\end{array}$ & $\begin{array}{l}7858 \\
370\end{array}$ & $\begin{array}{l}95.50 \\
4.50\end{array}$ & $\begin{array}{l}3975 \\
139\end{array}$ & $\begin{array}{l}96.62 \\
3.38\end{array}$ & $\begin{array}{l}3883 \\
231\end{array}$ & $\begin{array}{l}94.39 \\
5.61\end{array}$ & $<0.000$ I \\
\hline Number of visited clinics & $\begin{array}{l}I-2 \\
3-5 \\
\geq 6\end{array}$ & $\begin{array}{l}3448 \\
3756 \\
1024\end{array}$ & $\begin{array}{l}41.91 \\
45.65 \\
12.45\end{array}$ & $\begin{array}{l}|49| \\
1979 \\
644\end{array}$ & $\begin{array}{l}36.24 \\
48.10 \\
15.65\end{array}$ & $\begin{array}{l}1957 \\
1777 \\
380\end{array}$ & $\begin{array}{l}47.57 \\
43.19 \\
9.24\end{array}$ & $<0.0001$ \\
\hline Number of hypertension medications & $\begin{array}{l}1 \\
\geq 2\end{array}$ & $\begin{array}{l}6847 \\
1381\end{array}$ & $\begin{array}{l}83.22 \\
16.78\end{array}$ & $\begin{array}{l}3381 \\
733\end{array}$ & $\begin{array}{l}82.18 \\
17.82\end{array}$ & $\begin{array}{l}3466 \\
648\end{array}$ & $\begin{array}{l}84.25 \\
15.75\end{array}$ & 0.0122 \\
\hline Immigration status & $\begin{array}{l}\text { Permanent resident } \\
\text { Marriage immigrant } \\
\text { Naturalized resident }\end{array}$ & $\begin{array}{l}- \\
- \\
-\end{array}$ & $\begin{array}{l}- \\
- \\
-\end{array}$ & $\begin{array}{l}971 \\
739 \\
2404\end{array}$ & $\begin{array}{l}23.60 \\
17.96 \\
58.43\end{array}$ & $\begin{array}{l}- \\
- \\
-\end{array}$ & $\begin{array}{l}- \\
- \\
-\end{array}$ & - \\
\hline
\end{tabular}

Abbreviation: $\mathrm{CCl}$, Charlson Comorbidity Index.

\section{Medication Possession Ratio}

We calculated the MPR during a 3-year follow-up period by dividing the sum of the total prescription days by the total number of follow-up days and multiplying by 100 (Figure 2). The overall mean MPR was lower in immigrants than in native-born Koreans $(56 \%$ vs. $70 \%, p<0.0001$ ). The adherence rate (MPR $\geq 80 \%$ ) was also lower in immigrants than in native-born Koreans $(46.2 \%$ vs. $61.9 \%, p<0.0001)$. The mean MPR was the highest in the earliest period and gradually decreased over time in both immigrants and native-born Koreans (Figure 2).

Figure 3 shows the overall mean MPR according to sex, age group, and the number of visited clinics. The adherence rates were similar by sex in immigrants (39.2\% and $40.0 \%$ for men and women, respectively). Older patients had higher adherence than younger patients. In addition, patients who had visited 1 or 2 clinics showed a higher MPR than patients who had visited 3 or more clinics both in immigrants and native-born Koreans. 
A

(\%) Mean MPR by sex

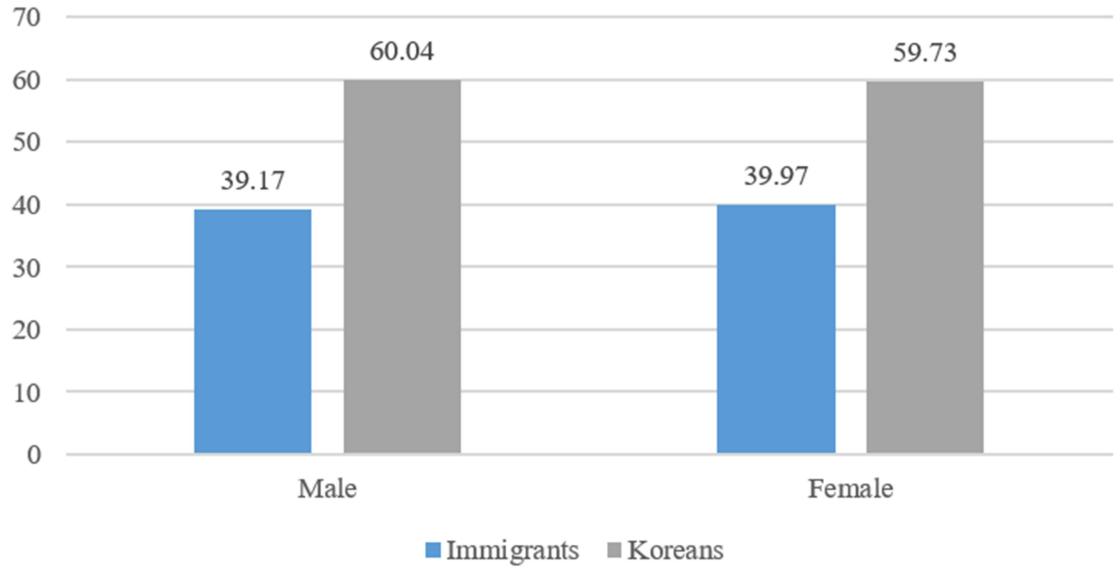

B

(\%) Mean MPR by age group

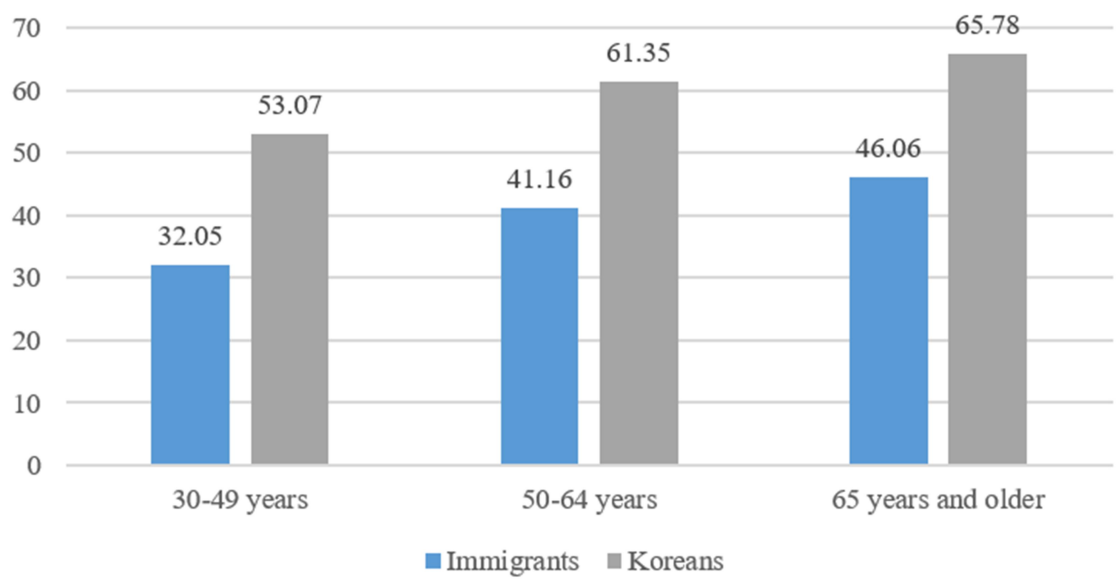

\section{C (\%) Mean MPR by number of visited clinics}

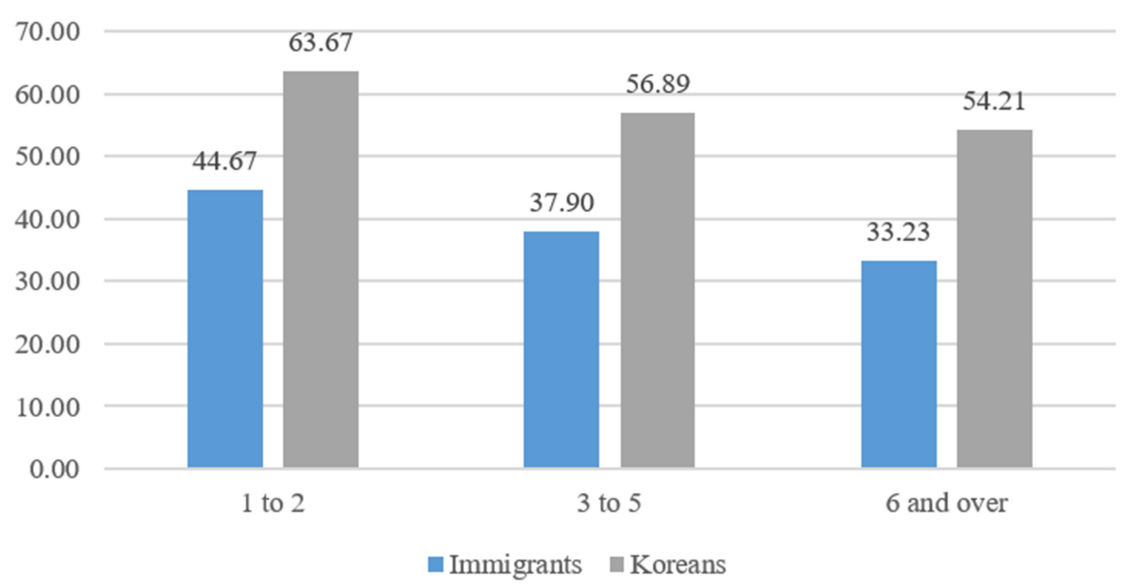

Figure 2 Mean MPR according to sex (A), age group (B), and the number of visited clinics $(\mathbf{C})$ between immigrants and native-born Koreans. MPR: medication possession ratio. 


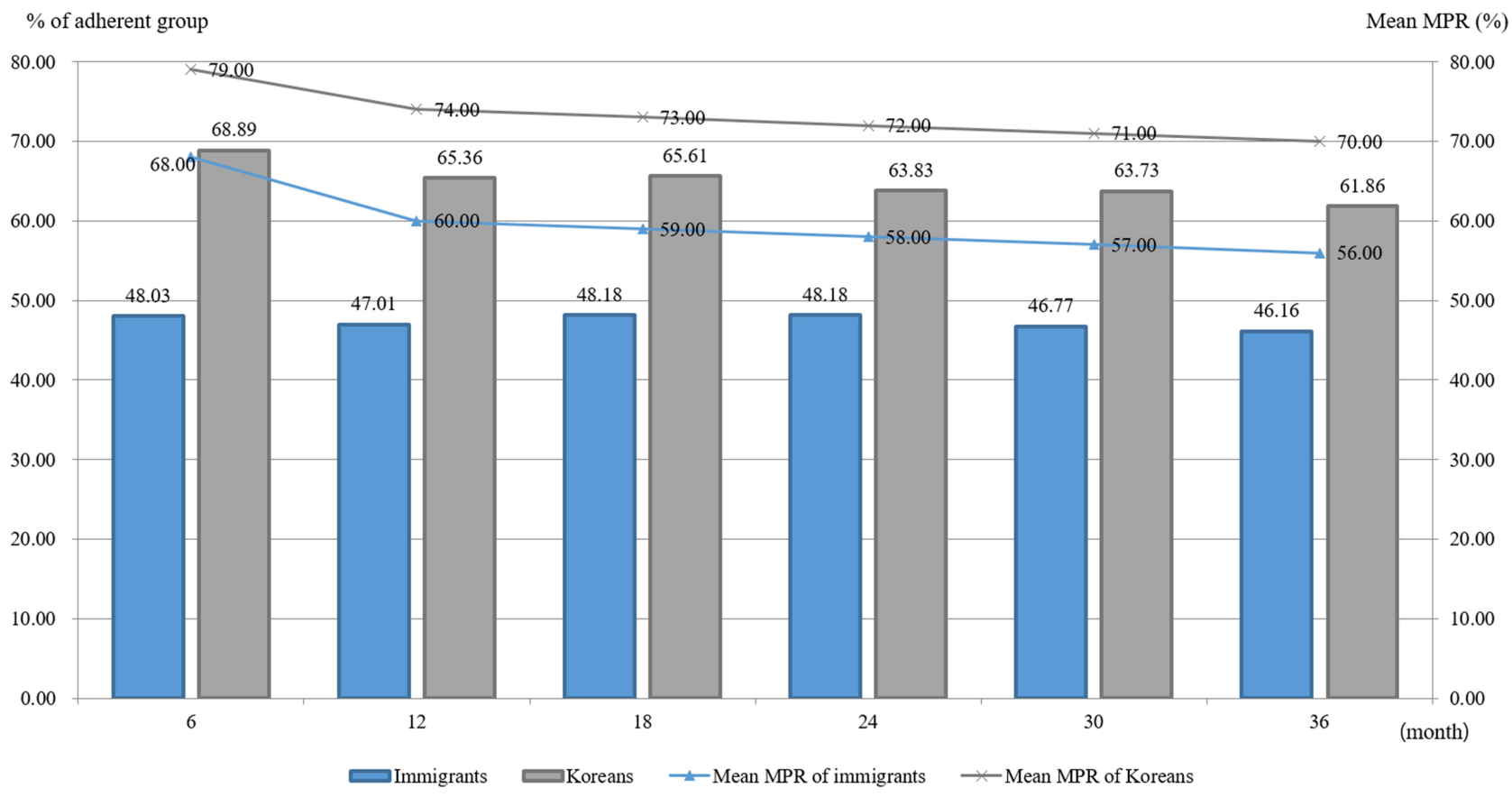

Figure 3 Medication adherence patterns for antihypertensive drugs over time between immigrants and native-born Koreans. MPR: medication possession ratio.

\section{Comparison of Adherence to Antihypertensive Drugs Between Immigrants and Native Koreans}

The overall OR of medication non-adherence was determined using a multivariate linear regression model. Immigrants showed a higher likelihood of non-adherence than native-born Koreans (OR, 2.01; 95\% CI, 1.83-2.21). Subgroup analyses presented that male and female immigrants had 2.00 and 2.07 times higher likelihoods of nonadherence than Korean male and female, respectively. All age groups of immigrants showed higher non-adherence than their native-born Korean counterparts, but as age increased, the OR decreased. According to the number of visited clinics (1-2 and $\geq 3$ ), immigrants showed 2.04 to 2.06 times higher non-adherence than native-born Koreans, which was a significant difference (Table 2).

\section{Risk Factors to Medication Adherence Among Immigrants}

We performed logistic regression analysis among immigrants to explore the risk factors associated with low medication adherence in immigrants (Table 3). Marriage immigrants had a 1.43 times higher likelihood of non-adherence than naturalized citizens. Advanced age groups (50-64 y and $\geq 65 \mathrm{y}$ ), compared to the younger age group (30-49 y), showed 0.66 to 0.59 times lower non-adherence to antihypertensive drugs, which was a significant difference. Medical Aid status increased the likelihood of non-adherence by $39 \%$ (OR, $1.39 ; 95 \% \mathrm{CI}, 1.05-1.85)$. The highest level of insurance contribution (OR, 0.58 ; 95\% CI, 0.45-0.73), having comorbidities (OR, 0.65 ; 95\% CI, 0.46-0.91), having diabetes (OR, $0.61 ; 95 \% \mathrm{CI}, 0.42-0.88$ ), and taking $\geq 2$ antihypertensives (OR, $0.65 ; 95 \% \mathrm{CI}, 0.55-0.77$ ) significantly contributed to a lower likelihood of non-adherence. On the contrary, visiting 3 to 5 clinics (OR, 1.31;95\% CI, 1.14-1.51), visiting 6 and more clinics (OR, 1.58; 95\% CI, 1.30-1.93), and having a CCI score of 1 or higher (OR, 1.36; 95\% CI, 1.17-1.59) were associated with a significantly higher likelihood of nonadherence to antihypertensive medication in immigrants (Table 3).

\section{Discussion}

We demonstrated additional evidence that immigrants are vulnerable to receiving non-optimal health care in their hypertension management. Their MPR was significantly lower, by approximately $20 \%$ than that of native-born Koreans and their rate of medication non-adherence was just over twice as high as that of native-born Koreans (OR, 2.01). Since hypertension management is a crucial aspect of preventing CVD complications and the resultant mortality, ${ }^{5}$ a well-established health care system for managing 
Table 2 Comparison of Non-Adherence to Antihypertensive Drugs Between Immigrants and Native-Born Koreans

\begin{tabular}{|c|c|c|}
\hline & $\begin{array}{l}\text { Adjusted } \\
\text { OR* }\end{array}$ & $95 \% \mathrm{Cl}$ \\
\hline Immigrants (ref: native-born Koreans) & 2.01 & $1.83-2.21$ \\
\hline \multicolumn{3}{|l|}{ Subgroup analysis ${ }^{\dagger}$} \\
\hline \multicolumn{3}{|l|}{ Sex (ref. native-born Koreans) } \\
\hline Men & 2.00 & $|.72-2.3|$ \\
\hline Women & 2.07 & $1.82-2.35$ \\
\hline \multicolumn{3}{|l|}{ Age group (ref. native-born Koreans) } \\
\hline $30 \sim 49$ years & 2.28 & $|.92-2.7|$ \\
\hline $50 \sim 64$ years & 2.05 & I.78-2.36 \\
\hline 65 years and older & 1.69 & $1.37-2.08$ \\
\hline \multicolumn{3}{|l|}{$\begin{array}{l}\text { Number of visited clinics (ref. native- } \\
\text { born Koreans) }\end{array}$} \\
\hline $1 \sim 2$ & 2.04 & $1.76-2.36$ \\
\hline 3 and over & 2.06 & I.82-2.34 \\
\hline
\end{tabular}

Notes: *Age, sex, and $\mathrm{CCl}$ were matched between immigrants and native-born Koreans. Therefore, the matched factors were not included in the regression model, which was adjusted for type of insurance, residential region, insurance premium quantiles, number of household members, comorbidities, diabetes mellitus, and number of antihypertension. †Comparison of non-adherence between immigrants and native-born Koreans stratified by sex, age group, and number of visited clinics. The regression model was adjusted for number of visited clinics, type of insurance, residential region, insurance premium quantiles, number of household members, comorbidities, diabetes mellitus, and number of antihypertension. Significant results made in bold type.

Abbreviations: OR, odds ratio; $\mathrm{Cl}$, confidence interval; $\mathrm{CCl}$, Charlson Comorbidity Index.

hypertension is needed to ensure high-quality health care both for immigrants and the native-born host population. In this context, the markedly lower adherence to antihypertensive drugs found in immigrants calls for urgent attention.

The primary objective of this study was to examine the association between having a usual source of care and adherence to antihypertensive drugs in immigrants. We hypothesized that medication adherence would be low in immigrants due to not utilizing stable medical services (absence of a usual source of care). Based on our results, the hypothesis was proven that immigrants were less likely to have a usual source of care, which made a significant negative contribution to medication adherence. The higher the number of visited clinics, the lower the likelihood of medication adherence was. Logistic regression analysis among immigrants also revealed consistent findings regarding potential risk factors. A similar result was reported in a study on health care disparity in Latinos in the USA. Having a usual source of care increased the likelihood of a blood pressure check in the past 2 years and a cholesterol check in the past 5 years. ${ }^{26}$ Immigrants of all ages are far less likely to have a usual
Table 3 Potential Risk Factors Significantly Associated with Non-Adherence to Antihypertensive Drugs in Immigrants by Logistic Regression Analysis

\begin{tabular}{|c|c|c|c|c|}
\hline Variables & Category & OR & $95 \%$ & \\
\hline Immigration status & $\begin{array}{l}\text { Naturalized } \\
\text { citizen } \\
\text { Permanent } \\
\text { resident } \\
\text { Marriage } \\
\text { immigrant }\end{array}$ & $\begin{array}{l}\text { Ref. } \\
\text { I.12 } \\
\text { I.43 }\end{array}$ & $\begin{array}{l}0.95 \\
1.19\end{array}$ & $\begin{array}{l}1.32 \\
1.72\end{array}$ \\
\hline Sex & $\begin{array}{l}\text { Male } \\
\text { Female }\end{array}$ & $\begin{array}{l}\text { Ref. } \\
0.91\end{array}$ & 0.80 & 1.04 \\
\hline Age group (years) & $\begin{array}{l}30-49 \\
50-64 \\
65 \text { and older }\end{array}$ & $\begin{array}{l}\text { Ref. } \\
0.66 \\
0.59\end{array}$ & $\begin{array}{l}0.56 \\
0.49\end{array}$ & $\begin{array}{l}0.77 \\
0.72\end{array}$ \\
\hline Type of insurance & $\begin{array}{l}\mathrm{NHI} \\
\text { Medical Aid }\end{array}$ & $\begin{array}{l}\text { Ref. } \\
1.39\end{array}$ & 1.05 & 1.85 \\
\hline Residential area & $\begin{array}{l}\text { Urban area } \\
\text { Rural area }\end{array}$ & $\begin{array}{l}\text { Ref. } \\
0.88\end{array}$ & 0.65 & 1.21 \\
\hline $\begin{array}{l}\text { Level of insurance } \\
\text { contribution }\end{array}$ & $\begin{array}{l}\text { Low } \\
\text { Middle } \\
\text { High }\end{array}$ & $\begin{array}{l}\text { Ref. } \\
1.03 \\
\mathbf{0 . 5 8}\end{array}$ & $\begin{array}{l}0.89 \\
0.45\end{array}$ & $\begin{array}{l}1.20 \\
0.73\end{array}$ \\
\hline Living alone & $\begin{array}{l}\text { Yes } \\
\text { No }\end{array}$ & $\begin{array}{l}\text { Ref. } \\
1.14\end{array}$ & 0.99 & 1.31 \\
\hline $\begin{array}{l}\text { Number of visited clinics } \\
\text { (n) }\end{array}$ & $\begin{array}{l}I-2 \\
3-5 \\
6 \text { and over }\end{array}$ & $\begin{array}{l}\text { Ref. } \\
\text { I.3I } \\
\text { I.58 }\end{array}$ & $\begin{array}{l}1.14 \\
1.30\end{array}$ & $\begin{array}{l}1.51 \\
1.93\end{array}$ \\
\hline $\mathrm{CCl}$ score & $\begin{array}{l}0 \\
I \text { and over }\end{array}$ & $\begin{array}{l}\text { Ref. } \\
1.36\end{array}$ & 1.17 & 1.59 \\
\hline Comorbidity & $\begin{array}{l}\text { No } \\
\text { Yes }\end{array}$ & $\begin{array}{l}\text { Ref. } \\
\mathbf{0 . 6 5}\end{array}$ & 0.46 & 0.91 \\
\hline Diabetes & $\begin{array}{l}\text { No } \\
\text { Yes }\end{array}$ & $\begin{array}{l}\text { Ref. } \\
0.61\end{array}$ & 0.42 & 0.88 \\
\hline $\begin{array}{l}\text { Number of } \\
\text { antihypertensive drugs }\end{array}$ & $\begin{array}{l}1 \\
2 \text { and over }\end{array}$ & $\begin{array}{l}\text { Ref. } \\
0.65\end{array}$ & 0.55 & 0.77 \\
\hline
\end{tabular}

Note: Significant results are shown in bold type.

Abbreviations: OR, odds ratio; NHI, National Health Insurance; $\mathrm{CCl}$, Charlson Comorbidity Index.

source of care or to have seen a doctor in the past year if they had a health problem in a report published in New Jersey. ${ }^{27}$ Low-income undocumented immigrants are more likely to lack a usual source of care than their counterparts with citizenship or documentation in California $\operatorname{area}^{28}$ and have difficulties obtaining needed health care. ${ }^{29}$

A usual source of care has been defined as the particular medical professional, doctor's office, clinic, health center, or other places where a person would usually go if 
sick or in need of advice about his or her health. ${ }^{30}$ It is well known that primary care can lower the costs of care, improve health care quality through easy access to more appropriate services and referrals, and reduce inequities in population health. ${ }^{31}$ Many barriers prevent immigrants from being able to obtain full health care coverage and sufficient health care access. ${ }^{3}$ These include legal issues, lack of knowledge and awareness of the health system in a new country, ${ }^{32}$ previous experiences of health care, ${ }^{33}$ language and cultural barriers, ${ }^{34}$ different health beliefs and attitudes, ${ }^{35}$ and health care gaps in the host country's health system.

Since health care disparities among immigrants are not only a problem for immigrants themselves but ultimately place a major burden on the host country, health care systems that encourage everyone to register with a primary care doctor as a usual source of care would enhance immigrants' access to health care, ${ }^{36}$ thereby compensating for the health care gap, as has been the experience of other countries. ${ }^{18,20,22}$ Another suggestion would be to educate clinical staff to be aware of the characteristics of immigrants and to be trained in cultural competency, which can improve the degree to which immigrants can easily access health care. ${ }^{36,37}$

Hypertension is generally more common in men than in women worldwide. ${ }^{38}$ However, women were prevalent in this study, which reflects the high proportion of women among the marriage immigrants who were included in this study. Female immigrants accounted for 83.2\% (132391/ 159206) of marriage immigrants in 2018, according to Statistics Korea. ${ }^{39}$

Other potential risk factors include advanced age. However, age was associated with higher levels of medication adherence, which conforms to the general trend that older adults are more concerned about their health than their younger counterparts and contribute more to health care management. ${ }^{40}$ Economic factors were significantly associated with medication adherence, as shown by the findings that Medical Aid status (low income) increased non-adherence by $39 \%$, but high insurance contributions (high income) decreased the likelihood of non-adherence by 0.58 times.

Marriage immigrant status was significantly associated with a higher likelihood of medication non-adherence. An explanation for this may be that marriage immigration has started more recently to Korea than other immigrants and they are comparably younger, which might result in them having a lower level of access to regular health care services. Having comorbidities and more severe hypertension status (taking 2 or more medications) decreased nonadherence by 0.65 times, implying that these factors may have alerted immigrants to the need to care for their hypertension more proactively.

The MPR analysis showed low levels of medication adherence in immigrants, as the MPR in immigrants was almost $20 \%$ lower than that of native-born Koreans (56\% vs $70 \%$ ). Of particular note, a trend was noticed for the MPR reduction to be higher in the first year and then to stabilize during the follow-up period. This shows that medication adherence in the early period was important for long-term management. The immigrants who started to receive health care services might be more educated and capable of following the instructions of health care providers than those who were non-adherent. A recent report from the National Academies of Science, Engineering, and Medicine on American immigrants stated that in general, immigrants to the USA had comparable levels of education to native-born Americans and their educational attainment and performance were quite high. ${ }^{41}$ This result suggests that the appropriate education of immigrants at the initial treatment might improve medication adherence and disease management.

The main strength of this study is the use of wellstandardized and extensive KNHICD. This is the first study to include all immigrants with hypertension to verify the potential risk factors for medication non-adherence in the context of the usual source of care utilization. Through this approach, we could identify potential risk factors and obtained additional knowledge for use when preparing future strategic plans for health care in Korea. Nonetheless, we need to mention a few limitations. Due to the characteristics of claims data, which only include immigrants who were eligible to receive coverage through the NHI, the included immigrants might have been relatively stable in terms of their socioeconomic status. Therefore, extreme cases of health care problems in ineligible immigrants could not be addressed. Additionally, the treatment and medication information retrieved from the claims data did not contain uninsured items; therefore, the results of the analysis may have been inflated or deflated to some degree, which needs careful interpretation. However, we are confident that we provided an accurate big-picture overview of this health care gap and the associated modifiable risk factors. Lastly, MPR is calculated from prescribed information from KNHICD, so the results might be different from 
those of actual pill counting or pharmacy prescription fill data and should be interpreted with this in consideration.

In conclusion, having a usual source of care, financial stability, comorbidities, and taking $\geq 2$ medications reduced medication non-adherence among immigrants with hypertension. Therefore, the systematization of registering with primary care (a usual source of care) might be a modifiable health care strategy to improve health care outcomes in immigrants.

\section{Acknowledgment}

This study used NHIS-NHID data (NHIS-2018-1-042) made available by the National Health Insurance Service (NHIS). The authors declare no conflicts of interest with the NHIS. We would like to thank the NHIS for its cooperation.

\section{Funding}

This research was funded by the Basic Science Research Program through the National Research Foundation of Korea (NRF) (2017R1D1A1B03034121). However, the funding body had no influence on conducting the research or writing the manuscript.

\section{Disclosure}

The authors report no conflicts of interest for this work.

Hyemin Cho and Sohyun Jeong equally contributed as first authors.

\section{References}

1. Tucker CM, Torres-Pereda P, Minnis AM, Bautista-Arredondo SA. Migration decision-making among Mexican youth: individual, family, and community influences. Hisp J Behav Sci. 2013;35(1):61-84. doi: $10.1177 / 0739986312458563$

2. Nicolaou M, van Dam R, Stronks K. Acculturation and education level in relation to quality of the diet: a study of Surinamese South Asian and Afro-Caribbean residents of the Netherlands. J Hum Nutr Diet. 2006;19(5):383-393. doi:10.1111/j.1365-277X.2006.00720.x

3. Hammond W, Mohottige D, Chantala K, Hastings J, Neighbors H, Snowden L. Determinants of usual source of care disparities among African American and Caribbean Black men: findings from the National Survey of American Life. J Health Care Poor Underserved. 2011;22(1):157-175.

4. WHO. The top 10 causes of death. 2018; https://www.who.int/news-room /fact-sheets/detail/the-top-10-causes-of-death. Accessed Aug 3, 2019.

5. Gueyffier F, Boutitie F, Boissel J, Pocock S, Coope J, Cutler J. Effect of antihypertensive drug treatment on cardiovascular outcomes in women and men. A meta-analysis of individual patient data from randomized, controlled trials. Ann Intern Med. 1997;126 (10):761-767. doi:10.7326/0003-4819-126-10-199705150-00002

6. Guo F, He D, Zhang W, Walton R. Trends in prevalence, awareness, management, and control of hypertension among United States adults, 1999 to 2010. J Am Coll Cardiol. 2012;60(7):599-606. doi:10.1016/j. jacc.2012.04.026
7. Modesti PA, Calabrese M, Marzotti I, et al. Prevalence, Awareness, Treatment, and Control of Hypertension among Chinese First-Generation Migrants and Italians in Prato, Italy: the CHIP Study. Int J Hypertens. 2017;2017:1-8. doi:10.1155/2017/6402085

8. Ministry of Justice. e-Country Index. Statistics of Residing foreigner 2019; http://www.index.go.kr/potal/main/EachDtlPageDetail.do?idx_ $c d=2756$. Accessed Aug 05, 2019..

9. McWilliams J. Health consequences of uninsurance among adults in the United States: recent evidence and implications. Milbank $Q$. 2009;87(2):443-494. doi:10.1111/j.1468-0009.2009.00564.x

10. Wilper A, Woolhandler S, Lasser K, McCormick D, Bor D, Himmelstein D. Health insurance and mortality in US adults. Am J Public Health. 2009;99(12):2289-2295. doi:10.2105/AJPH.2008. 157685

11. Ritchey M, Chang A, Powers C, et al. Vital signs: disparities in antihypertensive medication nonadherence among Medicare part D beneficiaries-United States, 2014. MMWR Morb Mortal Wkly Rep. 2016;65(36):967-976. doi:10.15585/mmwr.mm6536e1

12. Kronish I, Ye S. Adherence to cardiovascular medication: lessons learned and future direction. Prog Cardiovasc Dis. 2013;55 (6):590-600. doi:10.1016/j.pcad.2013.02.001

13. Crowley M, Zullig L, Shah B, et al. Medication non-adherence after myocardial infarction: an exploration of modifying factors. $J$ Gen Intern Med. 2015;30(1):83-90. doi:10.1007/s11606-014-3072-x

14. Korea National Statistical Office. 2013 Korean National Health and Nutrition Examination Survey (KNHANES) 2014; https://knhanes. cdc.go.kr/knhanes/index.do. Accessed October 8, 2020. 06, 2019.

15. Jang S, Song H, Shin S. Development of Evalation Indicators for Antihypertensive Drugs. korea: Health Insurance Review and Assessment Service; 2008.

16. Park J, Shin Y, Lee SY, Park J-H. Antihypertensive drug medication adherence of national health insurance beneficiaries and its affecting factors in Korea. J Prev Med Public Health. 2007;40(3):249-258. doi:10.3961/jpmph.2007.40.3.249

17. Boswort H, Oddone E. A model of psychosocial and cultural antecedents of blood pressure control. J Natl Med Assoc. 2002;94(4):236-248.

18. Tu K. Hypertension management by family physicians Is it time to pat ourselves on the back? Can Fam Physician. 2009;55(7):684-685.

19. Margolius D, Bodenheimer T. Controlling Hypertension Requires a New Primary Care Model. Am J Manag Care. 2010;16(9):648-650.

20. Petrella RJ. Moving Forward: familyPhysicians \& Hypertension. Perspectives Cardiology. 2004;28-31.

21. Al-Ali KA, Al-Ghanim FA, Al-Furaih AM, Al-Otaibi N, Makboul G, El-Shazly MK. Awareness of hypertension guidelines among family physicians in primary health care. Alexandria J Med. 2013;49 (1):81-87. doi:10.1016/j.ajme.2012.07.003

22. Pilipovic-Broceta N, Vasiljevic N, Marinkovic J, et al. Assessment of hypertension chronic care model: pacic application in Bosnia and Herzegovina. PlosOne. 2018;13(8):e0202250. doi:10.1371/journal. pone. 0202250

23. Hall G, Sauer B, Bourke A, Brown J, Reynolds M, LoCasale R. Guidelines for good database selection and use in pharmacoepidemiology research. Pharmacoepidemiol Drug Saf. 2012;21(1):1-10. doi: $10.1002 /$ pds. 2229

24. Steiner J, Koepsell T, Fihn S, Inui T. A general method of compliance assessment using centralized pharmacy records: description and validation. Med Care. 1998;26(8):814-823. doi:10.1097/00005650198808000-00007

25. Hong J, Kang H. Oral Antihyperglycemic Medication Adherence and Its Associated Factors among Ambulatory Care with Adult Type 2 Diabetes Patients in Korea. Korean $J$ of Health Policy Admin. 2010;20(2):128-143. doi:10.4332/KJHPA.2010.20.2.128

26. Rodríguez MA, Bustamante AV, Ang A. Perceived quality of care, receipt of preventive care, and usual source of health care among undocumented and other Latinos. J Gen Intern Med. 2009;24 (Supp13):508-513. doi:10.1007/s11606-009-1098-2 
27. Lloyd K, Cantor JC, Gaboda D, Guarnaccia P. 2009 New Jersey Faily Health Survey: Health, Coverage, and Access to Care of New Jersey Immigrants. New Jersey, NY: RUTGERS Center for State Health Policy; 2011.

28. Lucia L. Towards Universal Health Coverage: Expandingmedi-Cal to Low-Income Undocumented Adults. Berkeley, CA: University of California, Berkeley Center for Labor Research and Education; 2019.

29. Consequences C, Services B, Medicine I. America's Uninsured Crisis: Consequences for Health and Health Care. 2009.

30. AHRG. Agency for Healthcare Research and Quality. MEPS Topics: Usual Source of Care. MEPS: Medical Expenditure Panel Survey. 2019. https://meps.ahrq.gov/mepsweb/data_stats/MEPS_topics.jsp? topicid=44Z-1. Accessed Aug 13, 2019..

31. Starfield B, Shi L, Macinko J. Contribution of Primary Care to Health Systems and Health. Milbank Q. 2005;83(3):457-502. doi:10.1111/ j.1468-0009.2005.00409.x

32. O’Donnell C, Higgins M, Chauhan R, Mullen K. They think we're OKand we know we're not'. A qualitative study of asylum seekers' access, knowledge and views to health care in the UK. BMC Health Serv Res. 2007;7(1):75. doi:10.1186/1472-6963-7-75

33. O’Donnell C, Higgins M, Chauhan R, Mullen K. Asylum seekers'expectations of and trust in general practice: a qualitative study. BJGP. 2008;58:870-876.

34. MacFarlane A, O’Donnell C, Mair F, et al. REsearch into implementation STrategies to supportpatients of different ORigins and language background in a varietyof European primary care settings (RESTORE): study protocol. Implementation Sci. 2012;7(1):111. doi:10.1186/1748-5908-7-111
35. Cooper M, Harding S, Mullen K, O’Donnell C. 'A chronic disease is a disease which keeps coming back ... It is like the flu': chronicDisease Risk perception and Explanatory Models among French- and Swahili-speaking African Migrants. Ethn Health. 2012;17(6):597-613. doi:10.1080/13557858.2012.740003

36. O'Donnella CA, Burns N, Maira FS, et al. Reducing the health care burden for marginalised migrants: thepotential role for primary care in Europe. Health Policy (New York). 2016;120(5):495-508. doi:10.1016/j.healthpol.2016.03.012

37. Vivo R, Krim S, Liang L, et al. Short- and long-term rehospitalization and mortality for heart failure in 4 racial/ethnic populations. $J$ Am Heart Assoc. 2014;3(5):e001134. doi:10.1161/JAHA.114. 001134

38. Sandberg K, Ji H. Sex differences in primary hypertension. Biol Sex Differ. 2012;3(1):7. doi:10.1186/2042-6410-3-7

39. Statistics Korea. Trend of marrige immigrants. 2018; http://www. index.go.kr/potal/main/EachDtlPageDetail.do?idx_cd=2819. Accessed October 8, 2020.

40. Rolnick SJ, Pawloski PA, Hedblom BD, Asche SE, Bruzek RJ. Patient Characteristics Associated with Medication Adherence. Clin Med Res. 2013;11(2):54-65. doi:10.3121/cmr.2013.1113

41. National Academies of Sciences E, and Medicine. The Intergration of Immigrants into American Society. Washington: DC; 2015.
Patient Preference and Adherence

\section{Publish your work in this journal}

Patient Preference and Adherence is an international, peer-reviewed, open access journal that focusing on the growing importance of patient preference and adherence throughout the therapeutic continuum. Patient satisfaction, acceptability, quality of life, compliance, persistence and their role in developing new therapeutic modalities and compounds to optimize clinical outcomes for existing disease states are major areas of interest for the journal. This journal has been accepted for indexing on PubMed Central. The manuscript management system is completely online and includes a very quick and fair peer-review system, which is all easy to use. Visit http:// www.dovepress.com/testimonials.php to read real quotes from published authors. 